\title{
CCS e amiloide A do leite de quartos mamários tratados na secagem com plasma rico em plaquetas autólogo, associado ou não a antibiótico
}

\author{
[CCS and Amyloid A of milk from breast quarters treated in drying with autologous \\ platelet-rich plasma, with or without antibiotics] \\ R.A. Terra ${ }^{1}$, A.S. Izidorio ${ }^{1}$, J.D. Assis ${ }^{2}$, A.C.S. Cunha ${ }^{2}$, L.A. Mendonça ${ }^{3}$, \\ G.S. Meireles ${ }^{1}$, A.Guimarães ${ }^{4}$, R.C.C.M. Botteon ${ }^{5}$ \\ ${ }^{1}$ Instituto Federal de Educação, Ciência e Tecnologia do Rio de Janeiro - Pinheiral, RJ \\ ${ }^{2}$ Aluno de graduação - Universidade Federal Rural do Rio de Janeiro - Seropédica, RJ \\ ${ }^{3}$ Técnica em Agropecuária autônoma - Pinheiral, RJ \\ ${ }^{4}$ Aluno de pós-graduação - Universidade Federal Rural do Rio de Janeiro - Seropédica, RJ \\ ${ }^{5}$ Universidade Federal Rural do Rio de Janeiro - Seropédica, RJ
}

\begin{abstract}
RESUMO
Este estudo teve como objetivo avaliar biomarcadores de mastite após terapia da secagem com plasma rico em plaquetas (PRP), associado ou não a antibiótico. Trinta e seis quartos mamários foram utilizados em três tratamentos (T): T1 - antibiótico (ATB), T2 - PRP e T3 - PRP + ATB. Amostras de leite foram coletadas antes da secagem (A1), no parto (D0) e 14, 30 e 60 dias pós-parto (D14, D30 e D60), para determinar contagem de células somáticas (CCS) e amiloide A (AA). O delineamento foi inteiramente ao acaso, com arranjo em parcelas subdivididas $\left(\right.$ SigmaPlot $^{\circledR}$ ). Dados de CCS foram transformados (log 10). As médias foram comparadas utilizando-se testes de Tukey ou Holm-Sidak $(\mathrm{P}<0,05)$. A CCS em A1 foi elevada em todos os grupos $(\mathrm{P}>0,05)$. No D30, CCS foi maior em T2 $(\mathrm{P}<0,05)$, igualando-se no D60. Não houve diferença na AA entre Ts em qualquer dia de coleta $(\mathrm{P}>0,05)$. Houve diferença nos momentos de coleta $(\mathrm{P}<0,05)$, A1 maior que D14 e D30. Houve uma correlação positiva fraca com CCS $(0,280)$. Os tratamentos foram semelhantes em manter a saúde da glândula mamária na lactação subsequente. O PRP intramamário pode ser usado para terapia de vaca seca em casos de mastite subclínica.
\end{abstract}

Palavras-chave: imunomodulador, bovinos, biomarcadores

\begin{abstract}
This study aimed to evaluate biomarkers of mastitis after autologous platelet rich plasma (PRP) dry cow therapy, associated or not with antibiotic, compared to conventional treatment. Thirty-six mammary quarters were used in three treatments (T): T1 - antibiotic, T2 - PRP and T3 - PRP + ATB. Milk samples were collected before drying (A1), on calving (D0) and at 14, 30 and 60 days postpartum (D14, D30 and D60), for Somatic Cell Count (CCS) and amyloid dosage A (AA). The design was completely randomized with arrangement in subdivided plots (SigmaPlot (B). Data from CCS were transformed in log10. Means were compared using the Tukey or HolmSidak tests, at a $95 \%$ confidence level $(P<0.05)$. CCS in Al was elevated in allgroups $(P>0.05)$. On D30 CCS was higher in $T 2(P<0.05)$, matching D60. There was no difference in AA among $T$ on any day of collection $(P>0.05)$. There was difference in collection moments $(P<0.05)$, Al different from D14 and D30. There was a weak positive correlation with CCS (0.280). Three treatments were similar in maintaining the health of the mammary gland at subsequent lactation. PRP intramammary can be used for dry cow therapy in subclinical mastitis.
\end{abstract}

Keywords: immunomodulator, cattle, biomarkers

\section{INTRODUÇÃO}

A mastite é a doença mais prevalente nos rebanhos leiteiros e a principal causa do uso de antimicrobianos em vacas leiteiras adultas (Pol e
Ruegg, 2007). Caracteriza-se por redução ou perda da capacidade secretora da glândula mamária, alterações físicas, químicas e organolépticas do leite (Zafalon et al., 2005), trazendo prejuízos que variam de acordo com a

Recebido em 5 de junho de 2019

Aceito em 4 de junho de 2020

E-mail: rosangela.terra@ifrj.edu.br 
intensidade do processo inflamatório, com a prevalência da doença no rebanho, com a patogenicidade dos agentes envolvidos e com o número e estágio de lactação (Detilleux, 2018). Além disso, a possibilidade de veiculação aos consumidores de micro-organismos patogênicos ou suas toxinas por meio do consumo de leite é um problema de saúde pública (Langoni, 2013).

A mastite pode se apresentar na forma clínica (MC) ou subclínica (MSC) e, nesta última, a principal característica utilizada para o diagnóstico é o aumento na contagem de células somáticas (CCS), devido à maior migração de células de defesa para a glândula mamária, considerando-se um limiar de 200.000 células/mL de leite para mamas sadias (Della Libera et al., 2010), o qual pode chegar a $5.000 \times 10^{3}$ células/mL de leite, dependendo da severidade $\mathrm{e}$ da extensão da infecção e do tipo de microorganismo envolvido, sendo um importante mecanismo de defesa contra infecções (Barber e Yang, 1998). Outros biomarcadores para mastite têm sido estudados. Nos bovinos, a amiloide A sérico (SAA) é uma das principais proteínas da fase aguda (Eckersall et al., 2001; Murata et al., 2004), e Hussein et al. (2018) sugeriram que sua medição no leite (MAA- milk amyloid A) para diagnosticar MSC é mais vantajosa do que CCS, pois essa proteína é indetectável no leite de animais sadios, não havendo outro fator que não a mastite para o aumento de sua concentração.

Entre os períodos críticos de alta incidência de mastite em vacas leiteiras, o período seco é bastante complicado por diversos fatores, como o estresse causado pela interrupção da ordenha e pela cessação dos cuidados diários de desinfecção dos tetos, além de o leite residual favorecer o desenvolvimento microbiano (Green et al., 2002). A aplicação de antibiótico de longa ação em todos os quartos mamários no momento da secagem tem sido o foco dos programas de controle da mastite subclínica, visando ao tratamento de casos subclínicos e à profilaxia no caso dos tetos não infectados (Berry e Hillerton, 2002; Bhutto et al., 2010), com permanência do princípio medicamentoso por período maior de tempo na glândula mamária (Green et al., 2002). No entanto, a terapia da vaca seca aumenta o potencial de desenvolvimento de resistência dos micro-organismos (Santos, 2013), o que resulta em grande pressão para a redução do emprego de antibióticos de forma desnecessária. Abordagens não antibióticas podem ser úteis para prevenir novas infecções durante o período seco, em rebanhos em que o risco de mastite ambiental é alto (Pyörälä, 2008).

O plasma rico em plaquetas (PRP) é um material autógeno obtido por meio da centrifugação de sangue venoso (Mello et al., 2006). Fatores de crescimento e outros compostos bioativos presentes no PRP desempenham um importante papel na reparação de tecidos e no estímulo dos mecanismos de defesa contra as infecções (Yuan et al., 2012), com potencial efeito imunomodulador. A interação de plaquetas com neutrófilos promove o recrutamento de mais neutrófilos e outros leucócitos ao tecido inflamatório; além disso, as plaquetas ativadas iniciam ou amplificam várias respostas de neutrófilos, incluindo fagocitose, produção de radicais de oxigênio e produção de armadilhas extracelulares dos neutrófilos (NETs - neutrophil extracellular traps) (Lisman, 2018). LangeConsiglio et al. (2014) e Evkuran Dal et al. (2019) demonstraram uma boa ação de concentrado plaquetário na resolução da resposta inflamatória da glândula mamária de bovinos. Os primeiros autores demonstraram maior eficácia associandose antibiótico intramamário ao concentrado plaquetário, inclusive com menores índices de reincidência, além do PRP ter sido mais eficaz do que antibiótico quando utilizado isoladamente em casos de mastite crônica.

Pelos efeitos do PRP no estímulo dos mecanismos de defesa contra as infecções, é provável que ele possa atuar de forma a induzir uma melhor resposta imunológica da glândula mamária durante o período seco, auxiliando no seu restabelecimento e em sua preparação para a lactogênese subsequente. $\mathrm{O}$ objetivo do presente trabalho foi avaliar biomarcadores de mastite (CCS e amiloide A) após terapia de vaca seca com PRP, associado ou não a antibiótico, em comparação ao tratamento convencional.

\section{MATERIAL E MÉTODOS}

O estudo foi aprovado pela Comissão de Ética no Uso de Animais da Universidade Federal Rural do Rio de Janeiro (Ceua/UFRRJ n ${ }^{\circ}$ 7731180816) e foi realizado de janeiro a julho de 2018. Foram selecionados animais com MSC de uma propriedade leiteira com 83 animais em lactação, localizada no Distrito de Dorândia, Barra do Piraí 
- RJ, na qual era utilizada ordenha mecânica. O manejo pré-ordenha consistia de lavagem dos tetos com água clorada apenas se houvesse muita sujidade, descarte dos primeiros jatos, imersão dos tetos em solução pré-dipping (1,7\% de ácido lático $+0,5 \%$ de peróxido de hidrogênio), secagem após 30 segundos com papel-toalha (uma folha por teto) e colocação de ordenhadeira. Ao final da ordenha, os tetos eram desinfetados com solução pós-dipping à base de clorexidina $0,5 \%$, e os animais, então, eram soltos ao pasto.

Foram selecionados 36 quartos mamários de vacas mestiças (Holandês x Zebu) ao final da lactação, as quais não haviam sido tratadas com antibiótico nos 30 dias antecessores e apresentavam mastite subclínica (reação positiva ao California Mastits Test - CMT). Os animais tinham entre quatro e oito anos, escore de condição corporal estava entre 2,5 e 3,5 (escala de 1,0 a 5,0 conforme Wildman et al. (1982)), e eles eram mantidos sob regime de pastejo, recebendo concentrado comercial de acordo com a produção de leite, além de mistura mineral completa e água sem restrição.

No último dia de ordenha (início do período seco), foram instituídos três tratamentos, sendo 12 quartos mamários por tratamento $(\mathrm{T}) . \quad \mathrm{O} \quad \mathrm{T} 1$ consistiu na infusão intramamária de antibiótico, considerado tratamento convencional, utilizandose fórmula comercial rotineiramente aplicada na fazenda (Matijet vaca seca ${ }^{\circledR}$, benzilpenicilina $G$ procaína $1,000 \mathrm{~g}$, benzilpenicilina $\mathrm{G}$ potássica 0,314g; sulfato de neomicina 0,735g, MSD Saúde Animal, Brasil). No T2, os quartos mamários foram tratados com infusão intramamária de PRP autólogo, em um volume de $10 \mathrm{~mL}$ por quarto, utilizando-se cânulas intramamárias descartáveis, idênticas às utilizadas na aplicação de antibiótico. Já no T3, cada quarto mamário recebeu infusão de PRP autólogo $(10 \mathrm{~mL})$, seguida de aplicação de antibiótico intramamário. As infusões foram precedidas de esgotamento total do úbere, antissepsia com álcool $70 \%$ e seguidas de massagem para melhor distribuição do produto na glândula e imersão dos tetos em solução pósdipping. Os animais foram examinados uma vez por semana, durante todo o período seco, a fim de se verificarem possíveis sinais de mastite clínica ou outras enfermidades.

O PRP foi obtido dos animais do T2 e do T3, conforme protocolo descrito por Marques et al.
(2014). Após antissepsia adequada da pele na região do pescoço, de cada animal foram coletados $450 \mathrm{~mL}$ de sangue em bolsa de transfusão contendo CPDA-1 (ácido cítrico, citrato de sódio, fosfato de sódio, dextrose e adenina), por punção venosa da jugular com cateter $16 \mathrm{~g}$ acoplado à bolsa, sendo constantemente homogeneizado. As bolsas foram acondicionadas em caixa isotérmica, sendo feita homogeneização periódica, até a chegada ao laboratório, em torno de $20 \mathrm{~min}$. Todo o manuseio do sangue foi realizado em capela de fluxo laminar e de forma estéril, sendo retiradas alíquotas de $15 \mathrm{~mL}$ em tubos tipo Falcon estéreis para proceder às centrifugações.

Foram realizadas duas centrifugações: a primeira a $400 \mathrm{~g}$ ( $g$-force) por 10min, na qual descartaramse $50 \%$ do plasma da parte superior e a fração de hemácias, e a segunda centrifugação a 800 g por 10min, quando $75 \%$ do plasma sobrenadante foi descartado (plasma pobre em plaquetas), restando os $25 \%$ do plasma considerado PRP, que foi acondicionado em frasco estéril e mantido em recipiente isotérmico contendo gelo, até a aplicação intramamária. Nesse processo, foram obtidos $40 \mathrm{~mL}$ de PRP de cada animal, objetivando-se a utilização de $10 \mathrm{~mL}$ em cada quarto mamário. Foi feita contagem de plaquetas diluindo-se $10 \mu \mathrm{L}$ de PRP em $1990 \mu \mathrm{L}$ de líquido de Brecher, procedendo-se ao preenchimento da câmara de Neubauer, a qual foi acondicionada em câmara úmida para repouso de $20 \mathrm{~min}$. Foram contadas plaquetas em cinco quadrados do retículo central, obtendo-se o número de plaquetas por $\mathrm{mL}$, por meio da multiplicação pela área, altura e diluição (no plaquetas x $5 \times 10 \times 200=$ plaquetas $/ \mathrm{mm}^{3}$ sangue). Uma pequena alíquota foi enviada ao laboratório de microbiologia, para cultura e isolamento (Chi et al., 2001), visando confirmar a esterilidade do hemoderivado.

Amostras de leite foram obtidas em frascos estéreis de $50 \mathrm{~mL}$ antes da secagem (A1), no dia do parto (D0) e aos 14, 30 e 60 dias após o parto (D14, D30 e D60, respectivamente), após antissepsia do teto e eliminação dos primeiros jatos. O material foi armazenado em caixas isotérmicas contendo gelo, até a chegada ao laboratório, onde foi dividido em duas alíquotas. Alíquotas de $40 \mathrm{~mL}$ de leite foram acondicionadas em recipientes contendo o conservante bronopol (2- bromo- 2- nitro -1,3- propanodiol na concentração de $8 \mathrm{mg}$ do ingrediente ativo para 
cada $40 \mathrm{~mL}$ da amostra). Os frascos foram homogeneizados por inversão por 10 vezes, de forma suave, e alocados em caixa de transporte específica, sendo, após $15 \mathrm{~min}$, feita inversão da mesma por mais 10 vezes, para total diluição do conservante. Em seguida, as amostras foram encaminhadas por transportadora para o Laboratório da Rede Brasileira de Qualidade do Leite (Clínica do Leite, Esalq/USP, Brasil) para análise de CCS por citometria de fluxo (células $/ \mathrm{mL}$ ).

Alíquotas de leite total foram congeladas a $-20^{\circ} \mathrm{C}$, em frascos tipo Falcon de $15 \mathrm{~mL}$, para posterior dosagem de amiloide A (AA), por meio do ensaio imunoenzimático (ELISA) do tipo sanduíche, utilizando-se kit comercial para SAA (CloudClone Corp. SEA885Bo for Serum Amyloid A), seguindo-se recomendações do fabricante. O uso de kit para SAA em amostras de leite foi feito anteriormente por Gerardi et al. (2009) e Thomas et al. $(2015,2016)$, e a primeira descrição da técnica foi feita por McDonald et al. (1991).

Amostras foram diluídas em 1:50 $(10 \mu \mathrm{L}$ da amostra em $490 \mathrm{~mL}$ de PBS), enquanto o padrão foi reconstituído em solução específica, sendo feitas diluições seriadas a partir da solução estoque, com concentração de $40 \mathrm{ng} / \mathrm{mL}$, obtendo-se as seguintes concentrações de AA: 10; $5 ; 2,5 ; 1,25 ; 0,625 ; 0,312 ; 0,156$ e $0 \mathrm{ng} / \mathrm{mL}$ (branco). Após o preparo das amostras e soluções-padrão, foram pipetados $100 \mu \mathrm{L}$ de cada amostra na placa, além das sete concentrações do padrão e do branco. A placa foi selada e incubada durante uma hora, a $37^{\circ} \mathrm{C}$. O líquido foi removido da placa, porém sem lavagem. Pipetaram-se 100 $\mu \mathrm{L}$ do reagente A (anticorpo primário) em cada poço e novamente a placa foi selada e incubada a $37^{\circ} \mathrm{C}$, por uma hora. Em seguida, a solução foi aspirada e os poços foram lavados por três vezes, com $350 \mu \mathrm{L}$ de solução de lavagem, deixando-se agir por um a dois minutos.

Após a última lavagem, toda a solução foi removida por inversão da placa em papel absorvente. A próxima etapa consistiu na adição de $100 \mu \mathrm{L}$ do reagente $\mathrm{B}$ (anticorpo secundário), seguida de incubação a $37^{\circ} \mathrm{C}$, por $30 \mathrm{~min}$, após selar a placa. Após esse processo, foram feitas cinco lavagens, conforme já descrito, e adicionados $90 \mu \mathrm{L}$ de substrato em cada poço, incubando-se a $37^{\circ} \mathrm{C}$, por $10-20 \mathrm{~min}$, protegendose a placa da luz com uma tampa plástica preta.
Nesse momento, a solução se tornou azulada. Então, $50 \mu \mathrm{L}$ de solução Stop foram acrescentados e o líquido ficou amarelado. Após ser verificada a ausência de bolhas no líquido dos poços, foi feita leitura imediata de densidade óptica em leitor de ELISA a $450 \mathrm{~nm}$ (Thermo Scientific - Multiskan GO).

A partir dos resultados de densidade óptica, os valores obtidos das soluções-padrão foram submetidos ao software SigmaPlot $^{\circledR}$, para obtenção de curva-padrão, em que a variável independente $\mathrm{y}$ foi representada pelas concentrações conhecidas e a variável dependente $\mathrm{x}$ correspondeu às absorbâncias. A equação foi obtida por regressão polinomial e, a seguir, calcularam-se as concentrações das amostras, multiplicando-se por 50, devido à diluição inicial.

O delineamento foi inteiramente ao acaso, com arranjo em parcelas subdivididas, sendo cada quarto mamário uma unidade experimental, três tratamentos, e as parcelas os momentos de coleta e de avaliações (A1, D0, D14, D30 e D60). A análise estatística foi efetuada utilizando-se o programa SigmaPlot $^{\circledR}$, empregando-se os testes de Kolmogorov-Smirnov para se verificar a normalidade dos dados. Os dados referentes à CCS sofreram transformação logarítmica (log base 10) para atingir normalidade. Para todas as variáveis, foram determinados as médias e o desvio-padrão. A avaliação entre os tratamentos nos diferentes tempos foi realizada por análise de variância para medidas repetidas, e as médias foram comparadas utilizando-se os testes Tukey ou Holm-Sidak, a um nível de confiança de $95 \%$ $(\mathrm{P}<0,05)$.

\section{RESULTADOS E DISCUSSÃO}

O método manual para obtenção do PRP descrito por Marques et al. (2014) foi eficiente para concentração de plaquetas com resultados bastante semelhantes aos obtidos pelos autores. A média de plaquetas no sangue foi de $290 \pm 40 \mathrm{x}$ $1000 / \mathrm{mL}$, enquanto no PRP a média foi de $2.477 \pm 500 \times 1000 / \mathrm{mL}$, o que representa um valor aproximadamente 10 vezes maior no PRP que no sangue (Tab. 1). De acordo com Marx (2004), para que o PRP seja considerado terapêutico, é necessário um ganho em concentração de 300$400 \%$ em relação ao sangue. Esse protocolo foi mais eficiente na concentração de plaquetas bovinas do que o método de dupla centrifugação 
utilizado por López et al. (2012), e o resultado foi bastante semelhante ao obtido por LangeConsiglio et al. (2015) também em bovinos. De todas as amostras de PRP, obteve-se resultado negativo no cultivo microbiológico, o que confirma as boas práticas na manipulação no laboratório que conservaram sua esterilidade, bem como a adequação do método para fins de utilização do PRP.

No dia do parto, dois animais do grupo tratado com PRP (T2) apresentaram cortes em um dos tetos, que resultaram em inflamação e risco de infecção da glândula mamária, sendo instituída antibioticoterapia intramamária. Por esse motivo, esses quartos mamários foram retirados das análises, ficando os grupos com as seguintes unidades experimentais: $\mathrm{T} 1 \mathrm{n}=12, \mathrm{~T} 2 \mathrm{n}=10$ e T3 $\mathrm{n}=12$. Na média, a CCS das amostras de leite colhidas no dia da secagem (A1) foi elevada em todos os grupos $(\mathrm{P}>0,05)$, conforme descrito na Tab. 2 .

Tabela 1. Contagem de plaquetas (x 1000/mL) do sangue e plasma rico em plaquetas (PRP) de seis vacas pertencentes ao plantel leiteiro de uma fazenda em Barra do Piraí-RJ

\begin{tabular}{|c|c|c|c|}
\hline \multirow[b]{2}{*}{ Animal } & \multicolumn{2}{|c|}{$\begin{array}{c}\text { Plaquetas } \\
\text { (x 1000/mL) }\end{array}$} & \multirow{2}{*}{$\begin{array}{c}\text { Porcentagem em relação ao } \\
\text { sangue }\end{array}$} \\
\hline & Sangue & PRP & \\
\hline 1 & 336 & 3290 & 979 \\
\hline 2 & 368 & 2650 & 720 \\
\hline 3 & 255 & 2870 & 1125 \\
\hline 4 & 347 & 2090 & 602 \\
\hline 5 & 355 & 2510 & 707 \\
\hline 6 & 330 & 3430 & 1039 \\
\hline
\end{tabular}

Valores de referência para bovinos: 90 a 235 x 1000/mL (Smith, 2006)

Tabela 2. Médias das contagens de células somáticas (x 1000) de 34 quartos mamários de nove vacas, pertencentes ao plantel leiteiro de uma fazenda em Barra do Piraí-RJ, submetidas a três tratamentos (T) na secagem $(\mathrm{T} 1=$ antibiótico $(\mathrm{ATB}) ; \mathrm{T} 2=$ plasma rico em plaquetas $(\mathrm{PRP}) ; \mathrm{T} 3=\mathrm{PRP}+\mathrm{ATB})$

\begin{tabular}{cccc}
\hline Dia de coleta & Tratamentos & \\
& ATB $(n=12)$ & PRP $(n=10)$ & ATB+PRP $(n=12)$ \\
\hline Secagem & $2562^{\mathrm{Aa}}$ & $3940^{\mathrm{Aa}}$ & $2745^{\mathrm{Aa}}$ \\
14 & $49^{\mathrm{Ab}}$ & $204^{\mathrm{Ab}}$ & $114^{\mathrm{Ab}}$ \\
30 & $47^{\mathrm{Ab}}$ & $389^{\mathrm{Bb}}$ & $28^{\mathrm{Ab}}$ \\
60 & $53^{\mathrm{Ab}}$ & $71^{\mathrm{Ab}}$ & $49^{\mathrm{Ab}}$ \\
\hline
\end{tabular}

Médias seguidas de letras diferentes (maiúsculas nas linhas e minúsculas nas colunas) diferem estatisticamente a um nível de confiança de $95 \%(\mathrm{P} \leq 0,05)$.

Após o parto, a maior média de CCS foi verificada no D30, no grupo tratado com PRP (T2), havendo diferença em relação ao T1 e ao T3. A CCS menor que 100 mil células/mL de leite no $\mathrm{T} 1$ em todos os momentos é condizente com a ausência de mastite nos animais desse grupo. No T2, a alta CCS indica reação inflamatória da glândula, MSC no D30 e remissão do processo no D60, apresentando CCS menor que 100.000 células $/ \mathrm{mL}$. O número de quartos mamários com mais de $200 \mathrm{mil}$ células $/ \mathrm{mL}$ de leite foi mais alto em D30 ( $\mathrm{T} 1=1 ; \mathrm{T} 2=4$ e $\mathrm{T} 3=1)$, ocorrendo diminuição de quartos com CCS indicativa de MSC aos 60 dias (T1=0; T2=1 e T3=1).
O aumento da celularidade do leite na presença de agentes patogênicos ocorre devido à migração de leucócitos do sangue para o lúmen alveolar e está relacionado à patogenicidade do agente envolvido (Souza et al., 2009). Além da mastite, outros fatores, principalmente a fase da lactação, influenciam a CCS do leite. Dessa forma, ao final da lactação, era esperada uma alta CCS. Nos três tratamentos, houve queda significativa da CCS pós-parto (Fig.1).

Por meio da leitura das concentrações das soluções-padrão de AA, foi gerada a equação y = $0,155-(1,276 * x)+\left(3,182 * x^{2}\right), \operatorname{com} R^{2}=99 \%$, obtendo-se as médias de AA nos diferentes dias de coleta dos três tratamentos (Tab. 3). Não houve 


\section{Terra et al.}

diferença entre os tratamentos em nenhum dia de coleta $(\mathrm{P}>0,05)$. Houve diferença nos momentos de coletas $(\mathrm{P}<0,05)$, quando amostras colhidas antes da secagem apresentaram médias mais elevadas, como era esperado devido às altas CCS, apresentando diferença de D14 e D30, com menores médias.

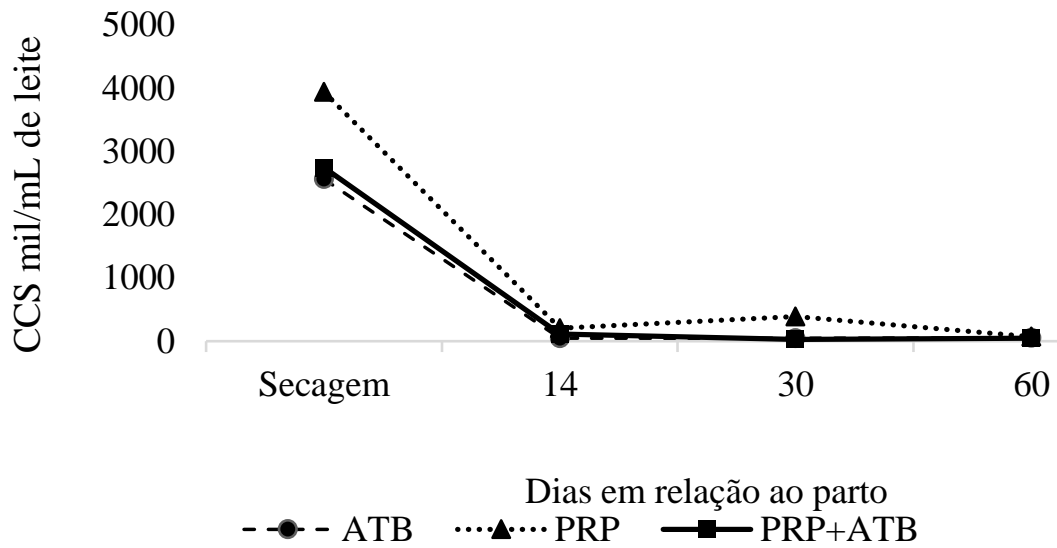

Figura 1. Médias de contagem de células somáticas (CCS) do leite de 34 quartos mamários de nove vacas pertencentes ao plantel leiteiro de uma fazenda em Barra do Piraí-RJ, submetidas a três tratamentos (T) na secagem $(\mathrm{T} 1$ = antibiótico $(\mathrm{ATB}) ; \mathrm{T} 2$ = plasma rico em plaquetas $(\mathrm{PRP}) ; \mathrm{T} 3=\mathrm{PRP}+\mathrm{ATB})$, com diferença em D30 no T2 $(\mathrm{P} \leq 0,05)$.

Tabela 3. Médias e desvio-padrão de amiloide A $(\mathrm{ng} / \mathrm{mL})$ no leite de 34 quartos mamários de nove vacas pertencentes ao plantel leiteiro de uma fazenda em Barra do Piraí-RJ, submetidas a três tratamentos (T) na secagem $(\mathrm{T} 1=$ antibiótico $(\mathrm{ATB}) ; \mathrm{T} 2=$ plasma rico em plaquetas $(\mathrm{PRP}) ; \mathrm{T} 3=\mathrm{PRP}+\mathrm{ATB})$

\begin{tabular}{ccccc}
\hline Dia de coleta & TTB $(\mathrm{n}=12)$ & PRP $(\mathrm{n}=10)$ & PRP+ATB $(\mathrm{n}=12)$ & Médias \\
\hline Antes da secagem & $687,80 \pm 8,23$ & $684,87 \pm 8,23$ & $968,77 \pm 8,23$ & $780,48^{\mathrm{A}}$ \\
0 & $369,45 \pm 8,23$ & $631,11 \pm 8,23$ & $584,82 \pm 8,23$ & $528,46^{\mathrm{AB}}$ \\
14 & $384,12 \pm 8,23$ & $609,50 \pm 8,23$ & $193,46 \pm 8,23$ & $395,69^{\mathrm{B}}$ \\
30 & $320,70 \pm 8,23$ & $285,10 \pm 8,23$ & $395,53 \pm 8,23$ & $333,78^{\mathrm{B}}$ \\
60 & $582,74 \pm 12,33$ & $411,77 \pm 9,27$ & $382,24 \pm 9,27$ & $458,92^{\mathrm{AB}}$ \\
\hline
\end{tabular}

Médias seguidas de letras distintas nas colunas diferem estatisticamente a um nível de confiança de $95 \%$ (P $\leq 0,05)$. Não houve interação entre tratamentos e dias de coleta, ou seja, o efeito de diferentes dias de coleta não depende do tratamento.

Eckersall et al. (2001) demonstraram que a AA é bastante específica para diferenciar animais sadios daqueles que apresentavam mastite. Haghkhah et al. (2010) e Nazifi et al. (2018) demostraram uma forte correlação entre CCS e AA, em grupos com diferentes graus de CCS, e uma proporção direta com a cultura microbiológica. Porém, Thomas et al. (2015) descreveram que valores basais dessa proteína são esperados devido ao fato de a AA ser sintetizada por células epiteliais da glândula mamária, podendo não se correlacionar com CCS. O presente trabalho apresentou correlação fraca positiva com CCS $(0,280)$, corroborando o fato de a amiloide A aumentar nos casos de aumento de
CCS. Domènech et al. (2014) demonstraram que AA do tipo 3 induz a involução da glândula mamária no período seco e a expressão de citocinas relacionadas à imunidade inata, justificando altas concentrações antes do parto.

As concentrações de AA em todos os tempos e tratamentos foram inferiores aos descritos por Evkuran Dal et al. (2019) em vacas com mastite subclínica. As concentrações após o parto são condizentes com o esperado para animais sem sinais de infecção intramamária (Fig. 2). Thomas et al. (2015) encontraram valores médios de AA de $0,96 \mu \mathrm{g} / \mathrm{mL}(960 \mathrm{mg} / \mathrm{mL})$ em vacas livres de mastite $(\mathrm{CCS} \leq 200 \mathrm{mil}$ células $/ \mathrm{mL}$ ), valores 
superiores aos obtidos no presente experimento. Em outro estudo, Thomas et al. (2018) demonstraram que as médias de proteínas da fase aguda podem variar dependendo do patógeno, sendo mais elevadas nos casos de mastite aguda, causada por patógenos de origem ambiental. Como os animais do presente experimento apresentavam MSC no momento da secagem, eram esperados valores inferiores de AA quando comparados ao artigo citado nos casos de MC.

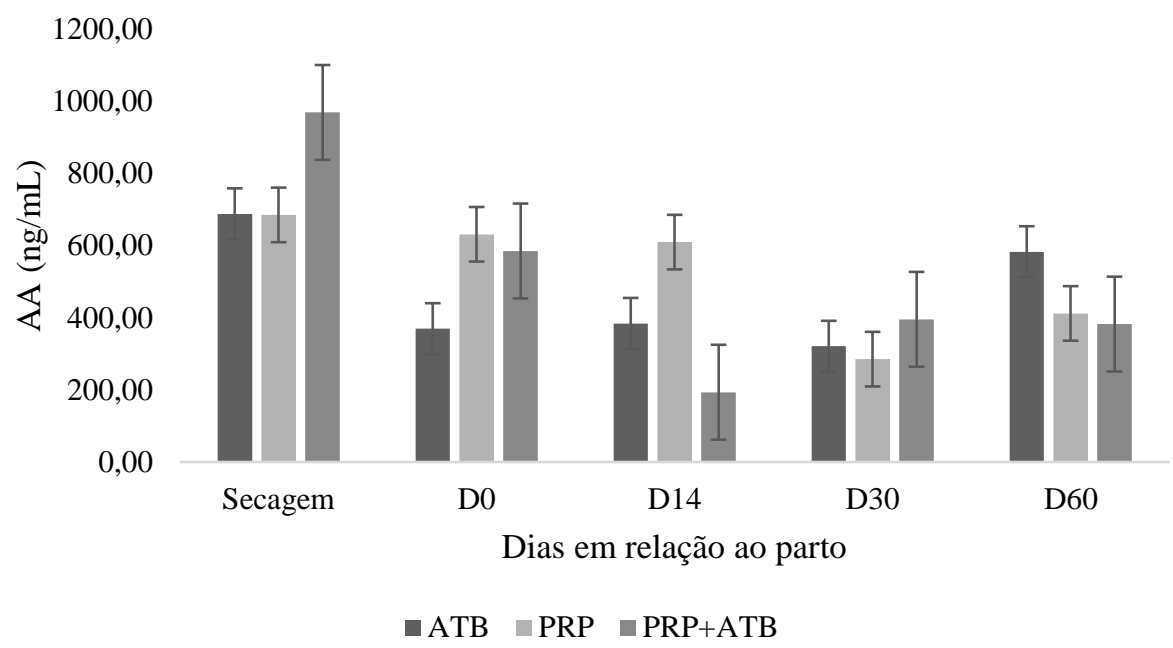

Figura 2. Médias e desvio-padrão de amiloide A dosada do leite (AA) de 34 quartos mamários de nove vacas pertencentes ao plantel leiteiro de uma fazenda em Barra do Piraí-RJ, submetidas a três tratamentos (T) na secagem $(\mathrm{T} 1=$ antibiótico $(\mathrm{ATB}) ; \mathrm{T} 2=$ plasma rico em plaquetas $(\mathrm{PRP}) ; \mathrm{T} 3=\mathrm{PRP}+\mathrm{ATB})$

A busca por tratamentos que minimizem o uso de antibióticos na pecuária leiteira tem sido o foco de muitos trabalhos, pois seu uso imprudente pode promover o desenvolvimento de resistência bacteriana, além da possibilidade de haver resíduos de antibióticos no leite e derivados lácteos que chegam ao consumidor (Berry e Hillerton, 2002). Na propriedade onde foi desenvolvido o presente experimento, há relatos de recusa do recebimento do leite no laticínio, devido à presença de resíduo de antibiótico, provavelmente por causa da mistura de leite de vacas no início da lactação, mesmo tendo sido respeitado o tempo de carência determinado pela bula da formulação (marca não mencionada utilizada em lactações anteriores). Esse é um problema com grande impacto econômico e o produtor é penalizado pela inutilização de grande volume de leite.

O uso do PRP pode ser uma alternativa para propriedades que querem minimizar o uso de antibióticos. O PRP não impediu a ocorrência de MSC nos primeiros 30 dias da lactação, considerando um limiar de CCS de $\leq 200.000$ células/mL de leite, porém mostrou-se semelhante aos demais tratamentos a partir desse período crítico. A média de CCS em D30, no entanto, ficou abaixo do preconizado pela legislação (Brasil, 2018), ou seja, o leite do conjunto estava dentro dos padrões para recebimento no laticínio. Nenhum quarto mamário desse grupo necessitou de antibioticoterapia durante toda a lactação, assim como no grupo que recebeu antibiótico.

Berry e Hillerton (2002) compararam os índices de novas infecções e MC em rebanhos com baixa CCS, tratados e não tratados com antibiótico, e encontraram índices superiores naqueles que não receberam tratamento algum. Vanhoudt et al. (2018) fizeram um estudo retrospectivo de terapia seletiva de vaca seca na Holanda, na qual animais com baixa CCS na secagem deixaram de receber antibiótico intramamário, demonstrando que não houve diferença nos índices de novas infecções durante o período seco, sendo possível reduzir a utilização de antibióticos. No presente trabalho, os quartos mamários apresentavam alta CCS no momento da secagem e os tratamentos instituídos foram equivalentes, demonstrando eficácia do PRP na manutenção da saúde da glândula mamária quando utilizado na secagem, mesmo com alta contagem de CCS, indicativa de MSC. 
Evkuran Dal et al. (2019) demonstraram redução significativa nas CCS em vacas com mastite subclínica tratadas com concentrado plaquetário, associado ou não a antibiótico, apresentando semelhança ao tratamento com antibiótico intramamário. Lange-Consiglio et al. (2014) relataram que o tratamento com concentrado plaquetário nos casos de mastite aguda foi semelhante ao tratamento com antibiótico ou antibiótico associado ao concentrado plaquetário e, nos casos de mastite crônica, o concentrado apresentou resultados melhores que o tratamento convencional. Diferentemente deste experimento, no qual foi utilizado PRP autólogo, os autores citados utilizaram sangue de vacas doadoras para obtenção do hemoderivado.

O tratamento intramamário no momento da secagem com PRP associado a antibiótico foi semelhante ao tratamento convencional. LangeConsiglio et al. (2014) relataram que a administração de fatores de crescimento por meio do PRP pode auxiliar na reparação dos tecidos lesados por resposta inflamatória prolongada, podendo justificar o benefício à associação.

\section{CONCLUSÕES}

Os tratamentos de vaca seca com PRP e PRP associado a antibiótico foram similares ao tratamento convencional com antibiótico na manutenção da saúde da glândula mamária na lactação subsequente. PRP intramamário pode ser utilizado para tratamento na secagem de vacas com mastite subclínica.

\section{REFERÊNCIAS}

BARBER, M.R.; YANG, T.J. Chemotactic activities in nonmastitic and mastitic mammary secretions: presence of interleukin-8 in mastitic but not nonmastitic secretions. Clin. Diagn. Lab. Immunol., v.5, p.82-86, 1998.

BERRY, E.A.; HILLERTON, J.E. The effect of selective dry cow treatment on new intramammary infections. J. Dairy Sci., v.85, p.112-121, 2002.

BHUTTO, A.L.; MURRAY, R.,D.; WOLDEHIWET, Z. Udder shape and treated lesions as potential risk factors for high somatic cell counts and intra-mammary infections in dairy cows. Vet. J., v.183, p.63-67, 2010.
BRASIL. Ministério da Agricultura Pecuária e Abastecimento. Instrução Normativa $n^{\circ} 77$, de 26 de novembro de 2018. Estabelece os critérios e procedimentos para a produção, acondicionamento, conservação, transporte, seleção e recepção do leite cru em estabelecimentos registrados no Serviço de Inspeção Oficial. Diário oficial da União, Brasília, 30 nov de 2018. ed. 230, Seção 1, p.10.

CHI, K.; ANDRADE, U.; FERREIRA, A. Sanitary program in dairy cattle. Arch. Vet. Sci., v.6, n.1, 2001.

DELLA LIBERA, A.M.M.P.; SOUZA, F.N.; BLAGITZ, M.G. et al. Avaliação de indicadores inflamatórios no diagnóstico da mastite bovina. Ciênc. Anim. Bras., v.1, p.726-731, 2010.

DETILLEUX, J. Tolerance to bovine clinical mastitis: Total, direct, and indirect milk losses. $J$. Dairy Sci., v.101, p.3334-3343, 2018.

DOMÈNECH, A. Sanitary program in dairy cattle. J. Dairy Sci., v.97, p.7595-7605, 2014.

ECKERSALL, P.D.; YOUNG, F.J.; McCOMB, C. et al. Acute phase proteins in serum and milk from dairy cows with clinical mastitis. Vet. Rec., v.148, p.35-41, 2001

EVKURAN DAL, G.; SABUNCU, A.; AKTARAN BALA, D. et al. Evaluation of intramammary platelet concentrate efficacy as a subclinical mastitis treatment in dairy cows based on somatic cell count and milk amyloid A levels. Kafkas Univ. Vet. Fak. Derg., v.25, p.357-363, 2019.

GERARDI, G.; BERNARDINI, D.; AZZURRA, C. et al. Use of serum amyloid A and milk amyloid $\mathrm{A}$ in the diagnosis of subclinical mastitis in dairy cows. J. Dairy Res., v.76, p.411, 2009.

GREEN, M.J.; GREEN, L.E.; MEDLEY, G.F. et al. Influence of dry period bacterial intramammary infection of clinical mastitis in dairy cows. J. Dairy Sci., v.85, p.2589-2599, 2002.

HAGHKHAH, M.; NAZIFI, S.; JAHROMI, A.G. Evaluation of milk haptoglobin and amyloid $\mathrm{A}$ in high producing dairy cattle with clinical and subclinical mastitis in Shiraz. Comp. Clin. Pathol., v.19, p.547-552, 2010.

HUSSEIN, H.A.; GOMAA, A.M.; KARAM, M. et al. Milk amyloid A as a biomarker for diagnosis of subclinical mastitis in cattle. Vet. World, v.11, p.34-41, 2018. 
LANGE-CONSIGLIO, A.; SPELTA, C.; GARLAPPI, R. et al. Intramammary administration of platelet concentrate as an unconventional therapy in bovine mastitis: first clinical application. J. Dairy Sci., v.97, p.62236230, 2014.

LANGE-CONSIGLIO, A.; CAZZANIGA, N.; GARLAPPI, R. et al. Platelet concentrate in bovine reproduction: effects on in vitro embryo production and after intrauterine administration in repeat breeder cows. Reprod. Biol. Endocrin., v.13, p.65-74, 2015.

LANGONI, H. Qualidade do Leite: utopia sem um programa sério de monitoramento da ocorrência de mastite. Pesqui. Vet. Bras., v.33, p.620-626, 2013.

LISMAN, T. Platelet-neutrophil interactions as drivers of inflammatory and thrombotic disease. Cell Tissue Res., v.371, p.567-576, 2018.

LÓPEZ, C.; GIRALDO, C.; CARMONA, J. Evaluación de un método de doble centrifugación en tubo para concentrar plaquetas bovinas: estudio celular. Arch. Med. Vet., v.44, p.109-115, 2012.

MARQUES, A.P.L.; BOTTEON, R.C.C.M.; CORDEIRO, M.D. et al. Padronização de técnica manual para obtenção de plasma rico em plaquetas de bovino. Pesqui. Vet. Bras., v.34, Supl.1, p.1-6, 2014.

MARX, R.E. Platelet-rich plasma: evidence to suport its use. J. Oral Maxillofac. Surg., v.62, p.489-496, 2004.

MCDONALD, T.L.; WEBER, A.; SMITH, J.W. A monoclonal antibody sandwich immunoassay for serum amyloid A (SAA) protein. J. Immunol. Methods, v.144, p.149-155, 1991.

MELLO, E.D.A; MELLO, G.P.S.; SILVA, L.A. et al. As bases biológicas do plasma rico em plaquetas. Rev. Fac. Odontol., v.11, p.91-95, 2006.

MURATA, H.; SHIMADA, N.; YOSHIOKA, M. Current research on acute phase proteins in veterinary diagnosis: an overview. Vet. J., v.168, p.28-40, 2004.

POL, M.; RUEGG, P.L. Treatment practices and quantification of antimicrobial drug usage in conventional and organic dairy farms in Wisconsin. J. Dairy Sci., v.90, p.249-261, 2007.
PYÖRÄLÄ, S. Mastitis in post-partum dairy cows. Reprod. Domest. Anim., v.43 Suppl.2, p.252-259, 2008.

SANTOS, M.V. Mastite bovina e o uso de antibióticos. Mundo Leite, v.61, p.18-20, 2013.

SMITH, B.P. Medicina interna degrandes animais. São Paulo: Manole, 2006. p.1019-1022.

SOUZA, G.N.; BRITO, J.R.F.; MOREIRA, E.C. et al. Variação da contagem de células somáticas em vacas leiteiras de acordo com patógenos da mastite. Arq. Bras. Med. Vet. Zootec., v.61, p.1015-1020, 2009.

THOMAS, F.C.; GERAGHTY, T.; SIMÕES, N.P.B.A. et al. A pilot study of acute phase proteins as indicators of bovine mastitis caused by different pathogens. Res. Vet. Sci., v.119, p.176$181,2018$.

THOMAS, F.C.; WATERSTON, M.; HASTIE, P. et al. Effect of pre-analytical treatments on bovine milk acute phase proteins. BMC Ve. Res., v.12, p.1-7, 2016 .

THOMAS, F.C.; WATERSTON, M.; HASTIE, P. et al. The major acute phase proteins of bovine milk in a commercial dairy herd. BMC Vet. Res., v.11, p.1-10, 2015.

VANHOUDT, A.; VAN HEES-HUIJPS, K.; VAN KNEGSEL, A.T.M. et al. Effects of reduced intramammary antimicrobial use during the dry period on udder health in Dutch dairy herds. $J$. Dairy Sci., v.101, p.3248-3260, 2018.

WILDMAN, E.E.; JONES, G.M.; WAGNER, P.E.; BOMAN, R.L. A dairy body condition scoring system and its relationship to selected production characteristics. J. Dairy Sci., v.65, p.495-501, 1982.

YUAN, T.; GUO, S.C.; HAN, P. et al. Applications of leukocyte and platelet-rich plasma (L-PRP) in trauma surgery. Curr.Pharm. Biotechnol., v.13, p.1173-1184, 2012.

ZAFALON, L.F.; NADER FILHO, A.; OLIVEIRA, J.V. et al. Comportamento da condutividade elétrica e do conteúdo de cloretos do leite como métodos auxiliares de de cloretos do leite como métodos auxiliares de diagnóstico na mastite subclínica bovina. Pesqui. Vet. Bra., v.25, p.159-163, 2005. 